\title{
Evaluation of Electron Density and Hounsfield Unit Values for 4DCT, NormalCT and BreathHoldCT in Lung SBRT Plan
}

\section{Akciğer SBRT Planlamada 4DCT, NormalCT ve BreathHoldCT için Elekton Yoğunluğu ve Hounsfield Unit Değerlerinin İncelenmesi}

\author{
İsmail Faruk Durmuş, Bora Taş \\ İstanbul Yeni Yüzyıl Üniversitesi Özel Gaziosmanpaşa Tıp Fakültesi Hastanesi Radyasyon Onkolojisi Bölümü, \\ İstanbul, Türkiye
}

Dergiye Ulaşma Tarihi: Dergiye Kabul Tarihi: Doi: 10.5505/aot.2018.45712

\section{ÖZET}

GİRIŞ ve AMAÇ: Radyoterapide tedavinin başarısı hedefe uygulanan dozun doğruluğu ile doğrudan ilişkilidir. Hedef volümün ve etrafındaki sağlıklı doku ve organların dozunu doğru hesaplamak kritik öneme sahiptir. Hesaplama algoritmalarının dozimetrik hesaplamalardaki en önemli etkeni, etkileşime girilen maddenin fiziksel özellikleridir. Solunum kaynaklı hareket ile tümör ve sağlıklı akciğer dokusu etkilenmektedir ve bu nedenle tomografi görüntülerinde tümörün ve akciğerin şekli, pozisyonu, yoğunluğu değişebilmektedir. Bu solunum kaynaklı değişimler, tümör hacminin büyüklüğünü, tedavi bölgesinin Hounsfield Unit ve elektron yoğunluğu değerlerini değiştirebilmektedir.

YÖNTEM ve GEREÇLER: Çalışmamızda 13 akciğer SBRT hastası için NormalCT, BreathHoldCT ve AverageCT (4DCT) taramaları yapıldı. Her bir teknikle taraması yapılan 13 hasta için; Gross tümör hacimleri (GTV) incelendi. Doz hesaplamasında önemli olan elektron yoğunluğu ve Hounsfield Unit değerleri üç tarama için karş̧laştırıldı.

BULGULAR: BreathHoldCT’ye göre NormalCT de \%19.3, AverageCT de \%31.3 GTV daha büyük bulundu. NormalCT ve AverageCT ile GTV de yoğunluk azalırken, etrafinda sağlıklı akciğer dokusunda yoğunluk artmaktadır. NormalCT ve AverageCT'de elektron yoğunluğu ve Hounsfield Unit değerleri sağlıklı akciğer dokusu için benzer bulunurken, GTV için NormalCT de daha yüksek değerler bulundu. GTV de elektron yoğunluğu ve Hounsfield Unit değerleri bakımından su eşdeğeri ortama benzer sonuçlar BreathHoldCT ile bulundu. AverageCT de ise en büyük farklar bulundu.

TARTIŞMA ve SONUÇ: Solunum hareketinden kaynaklı distorsiyon ve artifaklar BreathHoldCT ile minimize edilmektedir. BreathHoldCT ile daha solid ve sınırları daha belirgin görüntüler elde edilmektedir. BreathHoldCT ile elektron yoğunluğu ve Hounsfield Unit değerleri solunum kaynaklı hareketten bağımsız olarak daha doğru hesaplanabilmektedir. BreathHoldCT'ye göre NormalCT ve AverageCT de akciğer yoğunluğu artmakta ve bu durum sağlıklı akciğerdeki doz dağılımını etkilemektedir.

Anahtar Kelimeler: 4DCT Akciğer SBRT, Hounsfield Unit, Elektron Yoğunluğu

\begin{abstract}
INTRODUCTION: The success of radiotherapy treatment is related with accuracy of dose delivery directly. The exact dose calculation of target volume and healthy organs surround are critically important. The most important effect of calculation algorithms on dosimetric calculations is the physical properties of the material being interacted. Tumor and healthy lung tissue are affected by respiratory motion. therefore, the shape, position, density of the tumor and lung could change in tomography images. The serespiratory variations could change the size of tumor volume, the Hounsfield Unit and electron density of the treatment region. METHODS: In our study, normalCT, BreathHoldCT and AverageCT (4DCT) scans were performed for 13 lung SBRT patients. The tumor volumes (GTV) were investigated for 13 patients patients who were scanned with each technique. The electron density and Hounsfield Unit values which are important for dose calculation were compared for three scanning techniques.
\end{abstract}

RESULTS: We determined Tumor volume (GTV) 19.3\% larger at NormalCT and 31.3\% larger at AverageCT than BreathHoldCT. Density of GTV decreased in NormalCT and AverageCT, while healty lung tissiues's density were increasing. Electron density and Hounsfield Unit values at NormalCT and AverageCT were similar with healthy lung tissue. We obtained higher values For GTV, in NormalCT. In terms of electron density and 
Hounsfield Unit values at GTV were equivalent the water results with BreathHoldCT. The biggest difference was found in AverageCT.

DISCUSSION and CONCLUSION: Distortion and artifacts were caused by respiratory movement which were minimized by BreathHoldCT. More solid and clear boundary images could obtain with BreathHoldCT. Electron density and Hounsfield Unit values could be calculated more accurately, independent of respiratory motion With BreathHoldCT. Lung density is increasing in NormalCT and AverageCT, which affects the dose distribution in healthy lung.

Keywords: 4DCT Lung SBRT, Hounsfield Unit, Electron Density

\section{GíRIŞ}

Akciğer SBRT tümöre birkaç fraksiyonda yüksek radyasyon dozlarının uygulandığı bir tedavi yöntemidir (genellikle akciğerde 3-6 fraksiyonda 48-60 Gy). Hastaya uygulanan toplam doz, konvansiyonel radyoterapideki (genellikle 25-33 fraksiyonda 50-66 Gy) ile aynı olmasına rağmen SBRT'de fraksiyon başına yüksek radyasyon dozları, biyolojik olarak çok daha büyük radyasyon dozlarına eşdeğerdir. $\mathrm{Bu}$ sayede konvansiyonel Radyoterapiye göre biyolojik etkin doz (BED) daha fazladır (50-66 Gy'e karş1lık $\geq 100 \mathrm{~Gy}$ ). Akciğer SBRT'de non-koplanar 1şın demetleri ve küçük alan boyutları kullanılarak hedef dışında keskin bir doz düşüşü ve tümörün şekline uygun doz dağılımı elde edilebilmektedir.

Akciğer SBRT de iki önemli problem vardır. Bunlardan biri solunum kaynaklı hareket, diğer önemli problem ise doku inhomojenitesidir. İnhomojen ortamlarda doz dağılımında farklılıklar olmaktadır. Bunlar akciğer ortamında soğurulmanın zayıflaması, yanal menzilin artması, yüklü parçacık dengesizliği, re-buildup etkileridir. Solunum kaynaklı hareket ise hedefi iskalama ihtimali doğurmakta ve ayrica hareket, hedef ve etrafındaki sağlıklı dokunun elektron yoğunluğu (ED) ve Hounsfield Unit (HU) değerlerinin farklı hesaplanmasına neden olmaktadır. $\mathrm{Bu}$ iki problem kaynakl1 belirsizlikler ve zorluklar özellikle küçük alanlarda daha da artmaktadır. EORTC'a göre akciğer planlama ve uygulanmasında üç boyutta tümör hareketi hesaba katılmalı ve ona göre değerlendirilmelidir. Planlanan Target Volüm (PTV) marjlarını azaltmak içinde IGRT sistemleri kullanılmasını önerilmektedir (2). Akciğer RT'si için hareketi göz önünde bulundurularak; yavaş modda CT çekilebilir, nefes tutma veya diyafram kompresyonu uygulanabilir ya da son olarak solunumun herhangi bir fazında CT çekilip tedavi uygulanabilir $(1,2,3)$.

Radyoterapi de tedavi planlaması, tomografi taramalarından elde edilen geometrik ve yoğunluk bilgisine dayanmaktadır. Tarama sirasinda solunum hareketinin hasta anatomisini, pozisyonunu ve yoğunluğu değiştirdiği bilinmektedir. Solunuma bağlı olarak tümör, sağlıklı doku ve organlar büyük ölçüde hareket edebilirler, hareket miktarı ise hastanın anatomik ve fizyolojik durumuna, tümörün boyutu ve konumuna göre de değişmektedir. Tümör üç eksende (koronal, sagital ve transvers) de büyük hareketler yapabilmektedir. Bu durum planlanan ve gerçekte verilmek istenen doz dağılımları arasında önemli farklılıklara yol açabilmektedir. Tümör ve organ hareketliliğindeki belirsizliklerden dolayı, ICRU'nun 62 nolu raporuna göre konformal planlamalarda PTV geliştirilmiştir. PTV; solunum, kalp atımı gibi fizyolojik nedenlere bağlı iç organ hareketlerinden ve RT sırasında oluşabilecek hasta hareketleri, hastay1 konumlandırma hatalarından kaynaklanan belirsizlikleri kapsamaktadır $(3,4)$.

Çalışmamızda akciğer SBRT tedavisinde solunum kaynaklı hareketin tümör büyüklüğünü, tümör, sağlıklı doku ve organlarının elektron yoğunluğu ile HU değerlerini nasıl etkilediği araştırıldı.

\section{Bilgisayarlı Tomografi;}

Bilgisayarlı tomografi (BT), x-1şın tüpü ve hastanın karşısındaki detektörler ile senkronize hareket ederek tarama yapmaktadır. Temel olarak kolime edilmiş x-1şını kullanılarak incelenmek istenen bölgenin kesitsel görüntüsünü elde eden bir görüntüleme sistemidir. Bu kesitsel görüntüler birleştirilerek üç boyutlu görüntü oluşturulur. Ayrıca kesitler halinde ki görüntüler sayesinde iki boyutlu görüntülemede (röntgen) oluşan görüntülerin süperpoze (üst üste binme) olmasinı 
önlemektedir. Bununla birlikte kolimasyon sayesinde foton saçılması en aza indirilerek doku yoğunluk farklılıklarının daha belirgin hale gelmesi sağlanmaktadır. Görüntüler, incelenmek istenen bölgeden geçen her bir 1şının, o bölge boyunca her bir noktadaki doğrusal azaltma katsayıların toplamı ile elde edilir. Sonuç olarak elde edilen kesitsel görüntüler ise doğrusal azalım katsayılarının nümerik dağılımıdır. Tek bir geçirgenlik ölçümüyle her bir atenüasyon katsayıları belirlenemez. Çünkü fraksiyonel geçirgenlik eşitliğinde $\mu_{\text {doku }}$ tam olarak belli değildir. Fakat $\mathrm{x}$ 1şını kaynağının ve detektörün farklı yönelimlerinden elde edilen çoklu $\mathrm{x}$ 1şını geçirgenliği her bir atenüasyon katsayılarının hesaplanmasını sağlar $(5,6)$. Hesaplanan attenuasyon katsayıları HU sayısiyla temsil edilir. HU skalası -1024 ile +3071 aralığında değerler alır. Hava eşdeğeri ortamların HU değeri -1000 veya biraz daha büyük değer alırken kemik yapıları HU değeri +1000 civarında değer almaktadır. Hounsfield Unit (HU):

$$
H U_{(x, y, z)}=1000 x \frac{\mu_{d o k u}(x, y, z)-\mu_{s u}}{\mu_{s u}}
$$

Burada $\mathrm{x}, \mathrm{y}, \mathrm{z}$ bir vokselin koordinatıdır ve $\mu$ lineer atenüasyon katsayısıdır. HU sayısı, gri skalaya dönüştürülerek görüntü meydana gelmektedir $(5,6,7,8)$.

HU, atenüasyon katsayısıyla ilişkili olduğu için, elektron yoğunluğu hesaplanabilir. Elektron yoğunluğu birim hacim başına düşen elektron sayısı olarak tanımlanmaktadır. HU, elektron yoğunluğuyla lineer bir ilişkiye sahiptir. Ancak HU sayıs1 150'nin üzerinde, kemik gibi yüksek atom numaralı dokular atenüasyonu etkilediği için bu lineer ilişki bozulmaktadır (Şekil1) (5,6,7,8). Belirli bir dokunun HU değeri sabit değildir. Tüp voltajına $(\mathrm{kVp})$, çekim görüş alanına (FOV), saçılma koşullarına ve üretici firmanın reconstruction algoritmasına bağlı olarakta minimal düzeyde değişebilmektedir $(9,10)$.

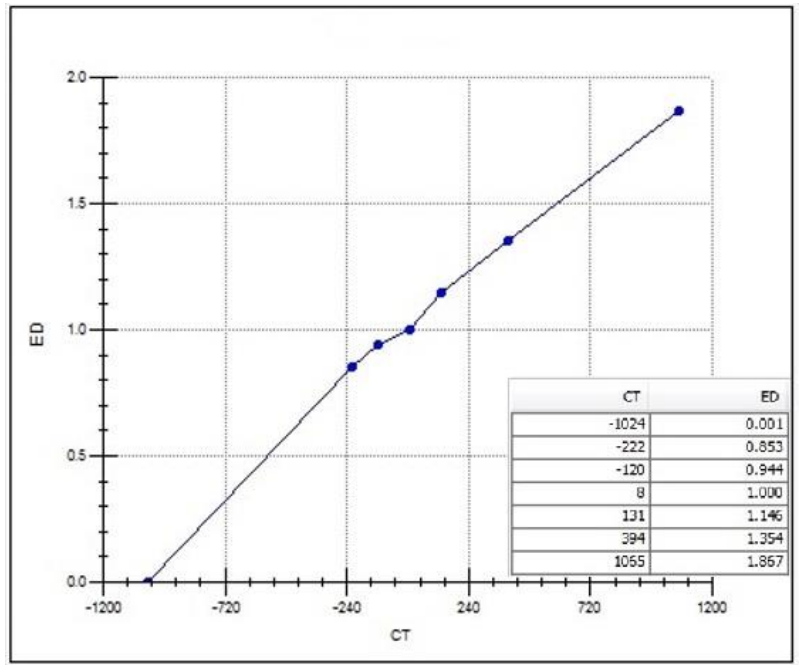

Şekil 1. Monaco Tedavi Planlama Sistemine yüklenen HU-ED eğrisi

\section{MATERYAL ve METOD}

13 Akciğer SBRT hastası için $1 \mathrm{~mm}$ kesit aralıklarında $120 \mathrm{kVp}, 75 \mathrm{mAs}$ de normal CT (nCT), BreathHold CT (BHCT) ve Average CT (AvCT)'leri Siemens ${ }^{\circledR}$ Biograph mCT (Knoxville, TN, USA) cihazı ile taramalar yapıldı. Her bir hasta için üç taramada aynı gün ve ardışık olarak yapıldı. 13 akciğer SBRT hastasının tümör lokalizasyonu sağ-sol ve üstorta-alt lob olarak gruplandırıldı.

nCT'ler tomografi cihazında yavaş modunda kesit başına 0.13 sn olacak şekilde taramalar yapıldı. AvCT için solunum döngüsünü 10 eşit zaman aralığına bölmekte ve solunumun \%10'luk dilimlerle maksimum soluk alma ve maksimum soluk verme arasındaki tüm fazlarda görüntüler elde edilmektedir. Solunumun tüm fazlarının taramasinı yapılarak elde edilen 4DCT görüntülerinden ortalama bir tomografi görüntüsü (AvCT) elde edildi. BHCT çekerken Catalyst $^{\mathrm{TM}}$ (C-RAD $\mathrm{AB}$, Sweden) yüzey tarama sistemiyle hasta belirlenen faz aralığına kadar nefes almakta ve solunumu o faz aralığında kısıtlanarak tomografi çekilmektedir (Şekil2). Derin solunum sonucu akciğer hacmi artmaktadır. Aynı zamanda soluk tutma ile akciğerler ve tümörün hareketi kisitlanmaktadır. 


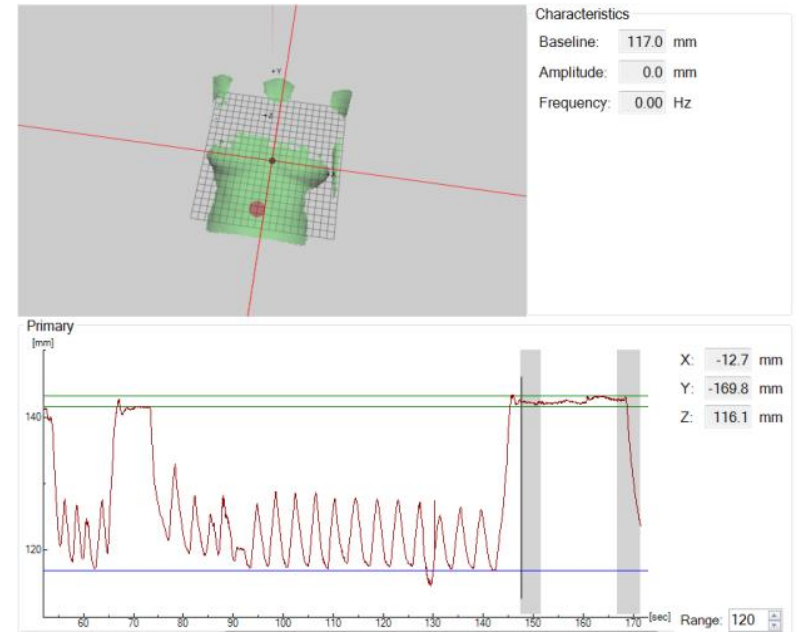

Şekil 2. Catalyst ${ }^{\mathrm{TM}}$ yüzey tarama sistemiyle derin solunum faz aralığının ayarlanması

Optik yüzey tarama sistemi olan Catalyst ${ }^{\mathrm{TM}}$ (CRAD AB, Sweden); LED (Light-emitting diode) ve CCD (Charge Coupled Device) kamera sistemi olan iki komponentten oluşur. Tedavi masasının ayak tarafına tavana monte edilir. Hastanın cildini taramak için, yakın görünür bölgede elektromanyetik dalga gönderip sonra hastanın cildinden yansıyan 1şık, kamera tarafindan toplanır. Hastanın pozisyonu kamera tarafindan toplanan 1şığın optik üçgenleme mantığıyla hesaplaması sonucu belirlenir. Catalyst ${ }^{\mathrm{TM}}$ yüzey tarama sisteminin özellikleri; frekansı 47-63 Hz, tarama 1şı̆̆ının dalga boyu 405nm (mavi), 528nm (yeşil), 624nm (kırmız1) dır. Tarama alan1; 800mm x 1300mm x 700mm (X, Y, Z). Ölçüm tekrarlanabilirliği; $0.2 \mathrm{~mm}$. Pozisyon doğruluğu 1mm den daha küçüktür $(11,12)$.

Tümör volümleri (GTV) 13 hasta için 3 farklı teknik ile taranan tomografi görüntüleri üzerine, Monaco 5.11 tedavi planlama sisteminde akciğer pencere aralığında radyasyon onkoloğu tarafindan konturlandı. Her üç teknik için ayrı ayrı konturlanan GTV için elektron yoğunluğu ve HU değerleri tedavi planlama sisteminde hesaplatild. Ayrica tümörün merkezinden $10 \mathrm{~cm}$ çapında küre oluşturularak, tümör ve çevresindeki sağliklı doku ve organların elektron yoğunluğu ve HU değerleri de hesaplatıldı. BHCT, AvCT, nCT ile yapılan karşılaştırmalar Friedman testi ile istatistik analizi yapıld1.

\section{BULGULAR}

13 hasta için ortalama tümör hacim BHCT ile 17.04mL hesapland1. nCT ile ortalama tümör hacmi $20.33 \mathrm{~mL}$ hesapland1. AvCT ile ortalama tümör hacmi $22.39 \mathrm{~mL}$ hesapland1.

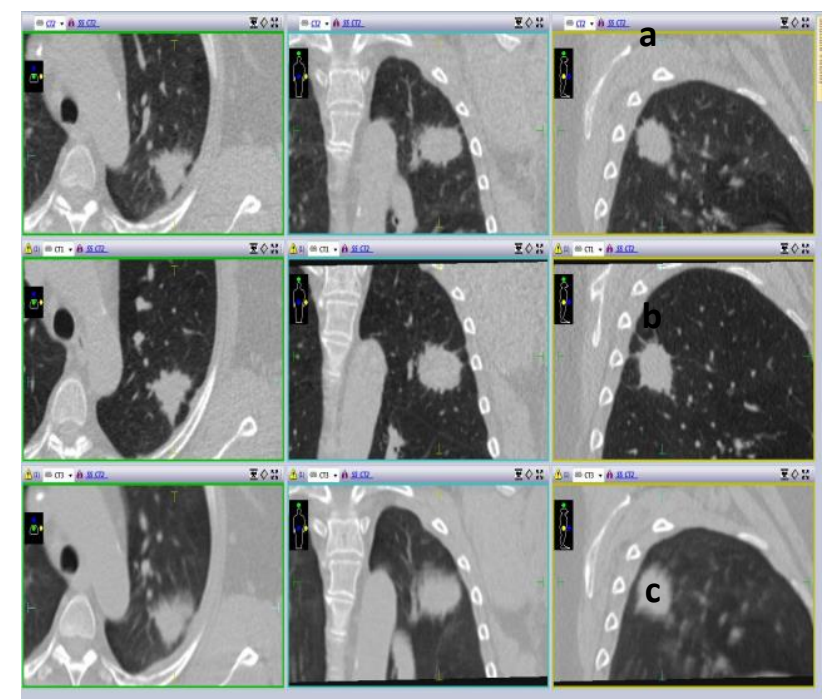

Şekil 3. $\mathrm{nCT}^{(a),} \mathrm{BHCT}$ (b), $\mathrm{AvCT}$ (b) ile koronal,sagital ve transvers eksende tümör görüntüsü.

BHCT ile solunum kaynaklı hareketi kısitlanan tümör, daha solid bir haldedir ve sınırlar daha keskin olarak belirlenir. BHCT'ye göre 13 hastada ortalama tümör hacmi nCT de \%19.3, AvCT de \%31.3 daha büyük hesaplanmıştır. Friedman istatistik analizine göre üç CT çekim tekniğine göre tümör hacimleri arasında bulunan farklar anlamlıdır $(\mathrm{p}<0.001)$. 
Tablo 1. 13 hasta için Tümör hacimleri (GTV) ve lokalizasyonları

\begin{tabular}{ccccc}
\hline & & Breath Hold CT & Normal CT & Average CT \\
\hline Hasta & Tümör Lokalizasyonu & Hacim $(\mathbf{m L})$ & Hacim $(\mathbf{m L})$ & Hacim $(\mathbf{m L})$ \\
\hline $\mathbf{1}$ & RLL & 0,31 & 0,52 & 0,66 \\
$\mathbf{2}$ & LML & 0,82 & 0,86 & 1,99 \\
$\mathbf{3}$ & LUL & 1,03 & 1,30 & 1,42 \\
$\mathbf{4}$ & LML & 1,22 & 1,29 & 1,60 \\
$\mathbf{5}$ & LLL & 1,38 & 1,50 & 1,78 \\
$\mathbf{6}$ & RUL & 1,63 & 1,78 & 2,22 \\
$\mathbf{7}$ & LLL & 3,60 & 4,05 & 6,96 \\
$\mathbf{8}$ & LML & 5,73 & 5,90 & 6,31 \\
$\mathbf{9}$ & RUL & 15,38 & 17,19 & 20,17 \\
$\mathbf{1 0}$ & LUL & 16,30 & 17,32 & 20,30 \\
$\mathbf{1 1}$ & RUL & 18,21 & 19,67 & 19,79 \\
$\mathbf{1 2}$ & RML & 45,15 & 48,40 & 59,49 \\
$\mathbf{1 3}$ & RLL & 110,75 & 144,45 & 148,39 \\
\hline Ortalama & & 17,04 & 20,33 & 22,39 \\
\hline
\end{tabular}

Elektron yoğunluğu; hedef hacim için ortalama değerler BHCT 0.85 , nCT 0.82 ve AvCT 0.79 hesapland1 (p:0.11). Hedef hacim merkezli $10 \mathrm{~cm}$ çapında küre için ortalama değerler BHCT 0.51, nCT 0.61, AvCT 0.61 olarak hesaplandı (p: 0.01). Hedef hacim için median değerler BHCT 0.94, nCT 0.92 ve AvCT 0.84 hesapland1 (p:0.006). Hedef hacim merkezli $10 \mathrm{~cm}$ çapında küre için median değerler BHCT 0.45, nCT 0.60, AvCT 0.54 olarak hesapland 1 (p: 0.002).

Tablo 2. 13 hasta için tümör (GTV) ve 10cm çapındaki bölgede elektron yoğunluğu değerleri

\begin{tabular}{|c|c|c|c|c|c|c|c|c|c|c|c|c|}
\hline \multirow[b]{3}{*}{ Hasta No } & \multicolumn{6}{|c|}{ Tümör Volümü } & \multicolumn{6}{|c|}{$10 \mathrm{~cm}$ Çapında Bölge } \\
\hline & \multicolumn{3}{|c|}{ TV-Mean ED } & \multicolumn{3}{|c|}{ TV-Median ED } & \multicolumn{3}{|c|}{$10 \mathrm{~cm}-$ Mean ED } & \multicolumn{3}{|c|}{ 10cm-Median ED } \\
\hline & BHCT & AvCT & nCT & BHCT & AvCT & nCT & BHCT & AvCT & nCT & BHCT & AvCT & $\mathrm{nCT}$ \\
\hline 1 & 0,76 & 0,63 & 0,681 & 0,866 & 0,618 & 0,716 & 0,248 & 0,355 & 0,378 & 0,121 & 0,203 & 0,215 \\
\hline 2 & 0,818 & 0,57 & 0,715 & 0,985 & 0,573 & 0,728 & 3 & 25 & & 09 & 0,447 & 0,515 \\
\hline 3 & 0,68 & 0,655 & 0,816 & 0,723 & 0,66 & 0,902 & 0,641 & 0,634 & 0,704 & 0,41 & 0,512 & 0,939 \\
\hline 4 & 0,78 & 0,795 & 0,801 & 0,91 & 0,903 & 0,961 & 0,231 & 0,217 & 0,425 & 0,121 & 0,342 & 0,425 \\
\hline 5 & 0,786 & 0,743 & 0,788 & 0,949 & 0,745 & 2 & 0,541 & 0,681 & 0,681 & 0,268 & 0,591 & 0,381 \\
\hline 6 & 0,785 & 0,789 & 0,797 & 0,919 & 0,923 & 0,926 & 0,637 & 0,597 & 0,549 & 0,943 & 0,611 & 0,313 \\
\hline 7 & 0,949 & 0,863 & 0,856 & 1,004 & 0,898 & 0,977 & 0,773 & 0,796 & 0,872 & 0,979 & 0,967 & 0,988 \\
\hline 8 & 0,964 & 0,873 & $0,8^{\circ}$ & 1,015 & 0,894 & 0,973 & 0,665 & 0,76 & 0,743 & 0,826 & 0,902 & 0,879 \\
\hline 9 & 0,745 & 0,739 & 0,759 & 0,878 & 0,788 & 0,826 & 0,343 & 0,475 & 0,304 & 0,193 & 0,304 & 0,334 \\
\hline 10 & 0,927 & 0,873 & 0,8 & 0,993 & 0,958 & 0,981 &, 53 & 0,818 & 0,681 & 0,278 & 0,359 & 0,682 \\
\hline 11 & 0,842 & 0,878 & 0,85 & 0,978 & 0,987 & 0,98 & 0,347 & 0,463 & 0,441 & 0,191 & 0,281 & 0,266 \\
\hline 12 & 0,993 & 0,885 & 0,927 & 1,021 & 0,986 & 1,015 & 0,551 & 0,652 & 0,698 & 0,291 & 0,557 & 0,82 \\
\hline 13 & 0,976 & 0,954 & 0,934 & 1,011 & 1,007 & 0,996 & 0,741 & 0,794 & 0,829 & 0,971 & 0,975 & 0,996 \\
\hline ORT & $\mathbf{0 , 8 5}$ & $\mathbf{0 , 7 9}$ & $\mathbf{0 , 8}$ & 0,94 & 0,84 & $\mathbf{0 , 9 2}$ & 0,51 & 0,61 & 0,61 & $\mathbf{0 , 4 5}$ & $\mathbf{0 , 5 4}$ & 0,60 \\
\hline STD & 0,10 & 0,11 & 0,07 & 0,08 & 0,14 & 0,09 & 0,17 & 0,18 & 0,17 & 0,33 & 0,25 & 0,28 \\
\hline
\end{tabular}


Hounsfield Unit; hedef hacim için ortalama değerler, BHCT -179.3, nCT -212.3 ve AvCT 253.3 hesapland1 (p:0.02). Hedef hacim merkezli $10 \mathrm{~cm}$ çapında küre için ortalama değerler, BHCT -505.7, nCT -416.5, AvCT 427.8 hesapland1 (p:0.09). Hedef hacim için median değerler, BHCT -89.62, nCT -125.15 ve AvCT -208.92 hesapland1 (p:0.06). Hedef hacim merkezli $10 \mathrm{~cm}$ çapında küre için median değerler, BHCT -582.3, nCT -353.6, AvCT 342.6 hesapland1 (p:0.02).

Tablo 3. 13 hasta için tümör (GTV) ve 10cm çapındaki bölgede Hounsfield Unit değerleri

\begin{tabular}{|c|c|c|c|c|c|c|c|c|c|c|c|c|}
\hline \multirow[b]{3}{*}{$\begin{array}{l}\text { Hast } \\
\text { a No }\end{array}$} & \multicolumn{6}{|c|}{ Tümör Volümü } & \multicolumn{6}{|c|}{$10 \mathrm{~cm}$ Çapında Bölge } \\
\hline & \multicolumn{3}{|c|}{ TV-Mean HU } & \multicolumn{3}{|c|}{ TV-Median HU } & \multicolumn{3}{|c|}{$10 \mathrm{~cm}-M e a n \mathrm{HU}$} & \multicolumn{3}{|c|}{ 10cm-Median HU } \\
\hline & BHCT & AvCT & nCT & $\begin{array}{c}\text { BHC } \\
\text { T }\end{array}$ & AvCT & nCT & $\begin{array}{c}\text { BHC } \\
\text { T }\end{array}$ & AvCT & nCT & $\begin{array}{c}\text { BHC } \\
\text { T }\end{array}$ & AvCT & $\mathrm{nCT}$ \\
\hline 1 & -278 & -422 & -373 & -208 & -443 & -351 & -782 & -681 & -656 & -911 & -834 & -823 \\
\hline 2 & -206 & -489 & -333 & -27 & -486 & -340 & -595 & -405 & -378 & -828 & -604 & -540 \\
\hline 3 & -365 & -390 & -233 & -344 & -404 & -167 & -384 & -391 & -321 & -477 & -543 & -126 \\
\hline 4 & -256 & -240 & -230 & -158 & -166 & -82 & -801 & -821 & -607 & -911 & 352 & -607 \\
\hline 5 & -245 & -308 & -247 & -109 & -324 & -147 & -486 & -345 & -344 & -773 & -469 & -424 \\
\hline 6 & -258 & -254 & -247 & -148 & -143 & -140 & -382 & -424 & -473 & -121 & -450 & -730 \\
\hline 7 & -65 & -194 & -173 & 11 & -171 & -45 & -248 & -231 & -149 & -41 & -68 & -19 \\
\hline 8 & -48 & -173 & -160 & 21 & -176 & -54 & -247 & -265 & -281 & -247 & -168 & -193 \\
\hline 9 & -290 & -309 & -280 & -194 & -283 & -247 & -692 & -562 & -739 & -843 & -739 & 345 \\
\hline 10 & -93 & -161 & -137 & -9 & -88 & -36 & -498 & -255 & -347 & -763 & 383 & -383 \\
\hline 11 & -185 & -149 & -178 & -43 & -21 & -38 & -686 & -571 & -594 & -845 & -760 & -775 \\
\hline 12 & -12 & -143 & -88 & 26 & -25 & 21 & -493 & -379 & -328 & -751 & -501 & -253 \\
\hline 13 & -31 & -62 & -88 & 17 & 14 & -1 & -280 & -231 & -197 & -59 & -50 & -69 \\
\hline ORT & $\begin{array}{c}\overline{179,38} \\
\end{array}$ & $\begin{array}{c}- \\
253,38\end{array}$ & $\dot{-}$ & $-89,62$ & $\begin{array}{c}- \\
208,92\end{array}$ & $\overline{-}$ & $-505,7$ & $\begin{array}{c}\mathbf{- 4 2 7 , 8} \\
175,8\end{array}$ & $\begin{array}{c}\mathbf{- 4 1 6 , 5} \\
175,1\end{array}$ & $-582,3$ & $\begin{array}{c}\mathbf{- 3 4 2 , 4} \\
385,7\end{array}$ & $\begin{array}{l}\mathbf{- 3 5 3 , 6} \\
329,6\end{array}$ \\
\hline STD & 111,41 & 119,97 & 83,27 & 110,16 & 159,45 & 117,71 & 186,82 & 9 & 9 & 329,81 & 5 & 9 \\
\hline
\end{tabular}

\section{TARTIŞMA}

Akciğer Radyoterapisinde solunum kaynaklı hareket büyük problemdir. Akciğer SBRT gibi yüksek dozların birkaç fraksiyonda uygulandığı ve küçük alanların kullanıldığ tedavilerde çok daha büyük belirsizliklere yol açmaktadır. Hem hedefi iskalamamak için hem de hedef ve etrafindaki doz dağılımının doğru hesaplanmasındaki belirsizlikleri belirleyip ona göre planlama yapmak kritik öneme sahiptir.

Doz dağılımını hesaplamak için HU değerlerinin elektron yoğunluğuna dönüştürülerek hesaplama yapılmaktadır. HU veya elektron yoğunluğundaki belirsizlikler direkt tedavi planında doz dağılımını etkilemektedir. Hem hedef bölge hem de hedef bölgenin etrafinda (özellikle yüksek doz alan bölgede) bu değerlerdeki belirsizliğin azaltılması gerekmektedir. BHCT ile solunum kaynaklı hareket kısıtlandığı için GTV elektron yoğunluğu ve HU değerleri su eşdeğeri ortamlara daha yakın bulundu. Su için elektron yoğunluğu yaklaşık $1.0 \mathrm{gr} / \mathrm{cm}^{3}$. 13 Hasta için mean elektron yoğunluğu BHCT için 0.85 , AvCT için 0.79 ve nCT için 0.82 bulundu. Median elektron yoğunluğu ise BHCT için 0.94, AvCT için 0.84 ve $\mathrm{nCT}$ için 0.92 bulundu. HU değeri ise su için yaklaşık 0 dır. 13 Hasta için mean HU değeri BHCT için 179.3, AvCT için -253.3 ve nCT için -212.8 bulundu. Median HU değeri ise BHCT için 89.6, AvCT için -208.9 ve nCT için -125.1 bulundu. GTV de HU ve elektron yoğunluğu değerleri bakımından su eş değeri ortama en yakın sonuçlar BHCT taramaları ile elde edildi.

Eksternal Radyoterapide hedef optimum belirlenen doz ile işınlanırken, etrafında bulunan sağlıklı doku ve organları 
maksimum seviyede koruma amacına yönelik uygulanan bir tedavidir. Bu amaca yönelik olarak planlama sirasında hedefin ve etrafinın doz dağılımını doğru hesaplamak için radyasyonun etkileşime girdiği her bir noktanın elektron yoğunluğu ve HU değerinin doğruluğu önemlidir. Doz hesaplama algoritmalarının doğru hesaplaması için 1şının görüş alanındaki yani etkileşime girdiği tüm doku ve organların fiziksel özellikleri doğru belirlenmeli ve varsa belirsizlikler azaltılmalıdır. $\mathrm{Bu}$ nedenle çalışmamızda GTV'yi merkez alarak $10 \mathrm{~cm}$ çapında küre oluşturuldu. Bu kürenin elektron yoğunluğu ve HU değerleri üç farklı BT çekimleri için incelendi. $10 \mathrm{~cm}$ çapında küre daha çok akciğer dokusu içerdiği için $\mathrm{HU}$ ve elektron yoğunluğunun düşük olması beklenmektedir. Çalışmamızda HU değerleri BHCT de en düşük değerler elde edildi. AvCT ve nCT de daha yüksek değerler bulundu. Akciğer dokusunun $\mathrm{ED}$ ve $\mathrm{HU}$ en yakın sonuçlar BHCT taramaları ile elde edildi.

Hanley ve ark. akciğer tümörlerinin tedavisinde derin nefes nefes tutma (BH-CT) tekniğinin dozimetrik yararlarını ve fizibilitesini değerlendirmişlerdir. Tekniğin iki farklı özelliği vardır: Akciğer yoğunluğunu azaltan derin nefes alma ve akciğer tümörlerini hareketsiz kılan nefes tutma, böylece PTV marjlarını azaltmamızı sağlamaktadır. Daha küçük hacimde belirlenmiş ve ve akciğer yoğunluğu diğer tekniklere göre daha düşük bulunmuş CT ile daha doğru daha hassas tedavi uygulanabileceğini vurgulamışlardır (13).

Aarup ve ark. sanal akciğer fantomunda farklı akciğer yoğunluklarında, farklı doz hesaplama algoritmalarının $6 \mathrm{MV}$ ve 18MV enerjilerinde doz dağılımlarını karşılaştırmışlardır. Akciğer lobunun merkezinde $2 \mathrm{~cm}$ çapında tümör oluşturulmuş ve akciğer yoğunluğunu $0.01,0.1,0.2$, $0.4 \mathrm{gr} / \mathrm{cm}^{3}$ ayarlayarak hesaplamalar yapmışlar. Akciğer yoğunluğunu $0.1-0.4 \mathrm{gr} / \mathrm{cm}^{3}$ arasında değiştirdiklerinde, Monte Carlo (MC) algoritmasında 6MV için hedef doz \%89.2\%74.9 arasında, 18 MV için \%83.3-\%61.6 arasında değiştiğini bulmuşlardır. Pencil Beam (PB) algoritmasında akciğer yoğunluğu değişimi ile anlamlı bir fark bulamamışlar (14).
Sonuç olarak, Solunum hareketinden kaynaklı distorsiyon ve artifaklar BHCT ile minimize edilmektedir ve daha solid, ve sınırları daha belirgin görüntüler elde edilmektedir. BHCT ile elektron yoğunluğu ve HU değerleri solunum kaynaklı hareketten bağımsı olarak daha doğru hesaplanabilmektedir. BHCT'ye göre nCT ve AvCT de akciğer yoğunluğu artmakta ve böylece sağlıklı akciğerin aldığı dozu etkilemektedir (15). nCT ve AvCT arasinda sağlıklı akciğerde yoğunluk farkı çok azdır, elektron yoğunluğu ve HU değerleri ise benzerdir(16, 17). GTVde elektron yoğunluğu ve HU, BHCT de su eşdeğeri ortama en yakın bulunurken, nCT de AvCT'ye göre daha düşük elektron yoğunluğu ve HU değerleri elde edildi. BHCT referans alındığında, nCT de hedef hacim \%19.3, AvCT de \%31.3 daha büyük olarak hesaplanmıştır (18).

\section{REFERANSLAR}

1. Bezjak A, Bradley J, Gaspar L, Timmerman R.D, Papiez L, Gore E, Kong P. Seamless Phase I/II Study of Stereotactic Lung Radiotherapy (SBRT) for Early Stage, Centrally Located, Non-Small Cell Lung Cancer (NSCLC) In Medically Inoperable Patients. Radiation Therapy Oncology Group RTOG 0813; 2012

2. Senan S, De Ruysscher D, Giraud $P$, et al. Literature-based recommendations for treatment planning and execution in highdose radiotherapy for lung cancer. Radiother Oncol; 2004: 71: 139-146

3. International Commission on Radiation Units and Measurements. ICRU 62. Prescribing, recording and reporting photon beam therapy; 1999: (supplement to ICRU report 50) Report No: 62. Washington DC.

4. Keall, Paul J.; Mageras, Gig S.; Balter, James M.; Emery, Richard S.; Forster, Kenneth M.; Jiang, Steve B.; Kapatoes, Jeffrey M.; Low, Daniel A.; Murphy, Martin J.; Murray, Brad R.; Ramsey, Chester R.; Van Herk, Marcel B.; Vedam, S. Sastry; Wong, John W.; Yorke, Ellen. "The management of respiratory motion in radiation oncology report of AAPM Task Group 76a)." Medical Physics; 2006: 33(10): 3874-3900.

5. Kalendar W. Computed Tomography. Erlangen: Publicis Corporate Publishing; 2005.

6. Mundt AJ, Roeske JC. Intensity Modulated Radation Therapy A Clinical Perspective. Hamilton, USA: BC Decker Inc, 2005

7. Hendee WR. Ibbott SG, Hendee GE. Radiation Therapy Physics.3nd edition. New Jersey:Published by John Wiley\& Sons,Inc, 2005.

8. Knöös T. Dose Planning and Dose Delivery in Radiation Therapy, PhD. Thesis. Lund University, Malmö, Sweden. 1991. 
9. Das, IJ, Cheng, CW, Cao, $\mathrm{M}$ et al, CT imaging parameters for inhomogeneity correction in radiation treatment planning. J Med Phys. 2016;41:1-11.

10. Mahur M, Gurjar OP, Grover RK, Negi PS, Sharma R, Singh A, Singh M. Evaluation of Effect of Different Computed Tomography Scanning Protocols on Hounsfield Unit and Its Impact on Dose Calculation by Treatment Planning System. Iran J Med Phys 2017; 14: 149-154.

11. Walter F, Freislederer P, Belka C, Heinz C, Söhn M, and Roeder F, "Evaluation of daily patient positioning for radiotherapy with a commercial 3D surface-imaging system (CatalystTM)," Radiat. Oncol; 2016: vol. 11, no. 1, p. 154.

12. CatalystTM 4D Tedavinin Değerlerndirilmesi'Teknik notlar: http://crad.se/content/uploads/2017/08/A4 CRAD_folder_Catalyst_pages.pdf

13. Hanley, J, Debois, M.M, Mah, D et al, Deep inspiration breath-hold technique for lung tumors (The potential value of target immobilization and reduced lung density in dose escalation). Int $J$ Radiat Oncol Biol Phys. 1999;45:603-611

14. LR Aarup, AE Nahum, $C$ Zacharatou, etal: The effect of different lung densities on the accuracy of various radiotherapy dose calculation methods: Implications for tumour coverage Radiother Oncol 91: 405- 414,2009

15. Hedin E, Back A, Chakarova R.Impact of lung density on the lung dose estimation for radiotherapy of breast cancer.Phsyics and Imaging in Radiation Oncology;2017:3;5-10

16. Tian, Y. et al. Dosimetric comparison of treatment plans based on free breathing, maximum, and average intensity projection CTs for lung cancer SBRT. Med. Phys;2012: 39, 2754-2760.

17. Zvolanek K, Ma R, Zhou C, Liang $X$, Wang S, Verma V, Zhu X, Zhang Q, Driewer J, Lin C, Zhen W, Wahl A, Zhou SM. Zheng D. Still equivalent for dose calculation in the Monte Carlo era? A comparison of free breathing and average intensity projection CT datasets for lung SBRT using three generations of dose calculation algorithms. (In press) Medical Physics;2017: DOI 10.1002/mp.12193.

18. Rietzel E. Chen GT. 4D imaging and treatment planning. In New Technologies in Radiation Oncology;2006: pages 81-97. Springer, BerlinHeidelberg, Germany. 